\title{
Developing Science Fiction among Kindergarten Children
}

\author{
Amani Majid ${ }^{1}$, Randa El Deeb ${ }^{2}$, Abdul Malik Taha ${ }^{3}$ \\ ${ }^{1}$ Ph.D. Researcher at Kindergarten Dep. Faculty of Education, Tanta University, Egypt \\ ${ }^{2}$ Professor at Kindergarten Dep, Faculty of Education, Tanta University, Egypt \\ ${ }^{3}$ Professor at Curricula and Teaching Methods' Dep, Faculty of Education - Tanta University, Egypt
}

\begin{abstract}
The aim of the current research is to verify the possibility of developing science fiction skills among kindergarten children by using some scientific concepts that can develop science fiction among kindergarten children and preparing a set of scientific activities that work to develop that kind of imagination among kindergarten children, the research sample included second-level children From kindergarten from 5-6 years, where the number of kindergarten children (30) was 60, and the period of application of the program was three times a week for a period of three months, and the study tools included (science fiction scale - a note card for children during science fiction activities). The results of the study in the presence of a statistically significant difference between the mean scores of the children in the pre- and post-application in favor of the post-sci-fi scale.
\end{abstract}

Keywords: kindergarten_Fiction_ science fiction.

\section{Introduction}

The kindergarten stage is one of the most important stages that a person goes through in his life, as it contributes to the formation of the child's personality.

The future, and one of the most important features of this stage is the imagination, as the kindergarten child is characterized by a broad imagination that needs support from those around, With it, the imagination is considered the greatest investment of any human wealth within any modern society, as it is the way to make these human energies a reflection of the present, the leaders of the future, the makers of civilization, and scientific progress. Whereas children are the men of tomorrow, and they are humanity's hope for a better life[1]

The real continuity and development of human civilization depends on building these children, and in a way that nourishes their minds from the objective scientific culture that was and

still contributes a great role in stimulating the human imagination and pushing for thinking,

innovation and creativity, without which man would not have been able to get rid of fear of nature and its manifestations and proceed to discoveries And the inventions that have brought mankind to its progress and development [2], and imagination is very important for children, as it occupies a wide space in children's mental 
activity, as the mental capabilities of young children grow continuously, and raising the imagination in children is extremely educational importance, as children in their early stages tend to be by nature. Fiction and stories

Fiction, cartoon films and science fiction stories, so these tendencies can be exploited in developing the imagination within them and mixing science with imagination in order to develop their capacities for creativity, innovation and imagination, as imagination is an essential component of children's scientific creativity, and the process of scientific education for children must be graduated, so we start with what It matches their experiences and perceptions, then gradually evolves towards more complex issues [3].

The age in which we live is the era of abundant scientific progress, which serves to exclude any of the societies that are characterized by laziness.

It cannot keep up with this scientific flow, and this scientific flow does not arise and appear except by the hands of the creators, and these creative people do not arise out of a vacuum, but care must be taken to search for them, care for them and raise them just as attention to rare strains of plants and animals [4]

The kindergarten institution is considered to have the most dangerous role in the upbringing and care of creative people. The child practices various activities in it, which are considered basic principles for developing his imagination and creativity [5]

And given that children are the cornerstone of building modern societies, and they are the real wealth of any nation, in addition to that attention must be paid to the proper scientific upbringing of children because they are preparing us for the future and thus crossing the gap between the community of developing nations and the community of developed nations The current study tries to identify the role of kindergarten institutions in developing Imagination and scientific creativity among her children.[6]
The age of informatics, in which we are currently living, accelerates pace in the field of science and technology, which requires attention to how to live life in the world of tomorrow, and to prepare children for scientific values, including the elements of imagination and creativity skills, which enables them to be able to employ the vocabulary of the era in development issues Keeping pace with global developments, and the importance of kindergarten institutions in this context comes through their development of imagination and scientific creativity skills among children, which contributes to the preparation and education of future scholars.[7]

The kindergarten institution is considered one of the important educational institutions that take care of the child in the most important stages of his life, and the importance of choosing the kindergarten stage is evident, where the kindergarten child is characterized by a broad imagination, and the imagination appears in the child from a very early age, so we find the child gives the characteristics of a living being on inanimate objects, and is attached On the various topics in the surrounding environment, using words from the inspiration of a cavalryman, and he may describe an image and give it details that are not present in reality, hence the importance of working on developing the child's imagination in general, which leads to his scientific creativity in particular [8]

It aims to raise the level of scientific culture among Americans, starting with kindergarten, and to build a new American citizen by 2061

The Japan Science and Technology Agency program aims to increase scientific and technical awareness of young children and teenagers, and includes the establishment of many science festivals for children, and the building of scientific museums that include a simplification of a number of scientific inventions for children[9]. 


\section{Methodology}

The current study aims to develop a proposed conception to activate the role that kindergarten institutions should play in developing the imagination and scientific creativity of their children, through the following:

1- Identify the conceptual framework of scientific imagination and creativity.

2- Explaining the features of the kindergarten institutions' role in developing the imagination and scientific creativity of their children

3- Identify the considerations that should be taken into account to enrich the role of kindergarten institutions to develop the imagination and scientific creativity of their children.

The importance of the study is evidenced by the importance of the subject of imagination and scientific creativity itself, as it plays a major role in creating a generation of scientists, and access to scientific discoveries, which helps the nation's progress.

The study contributes to the following aspects:

- Clarify the importance of the role of imagination and scientific creativity in the sound scientific upbringing of children and providing them with scientific concepts and scientific thinking skills.

- Directing the attention of specialists in education to the need to pay attention to imagination and scientific creativity directly in kindergarten curricula and emphasizing that science fiction is an integral part of the educational process system in kindergarten institutions and directing the attention of the designers of training courses for kindergarten teachers to the necessity of providing professional training courses for teachers related to the importance and development Imagination and scientific creativity in children.

The current study uses the descriptive approach, whereby it identifies the features of the role that kindergartens play in developing the imagination and scientific creativity of children, and defines a proposed conception to enrich this role.

the research sample included second-level children From kindergarten from 5-6 years, where the number of kindergarten children (30) was 60 , and the period of application of the program was three times a week for a period of three months, and the study tools included (science fiction scale - a note card for children during science fiction activities)

To test the validity of these hypotheses, the researcher calculated the average ranks of the pre and post measurements scores of kindergarten children for the group (control / experimental), and the researcher used a parametric statistical method represented in the "Wilcoxon Test" for related couples, on the science fiction test through the statistical package of the program " spss'

\section{Result}

Table (1) statistical significance for differences between arithmetic means of performance degrees for the study sample science fiction test

\begin{tabular}{|l|c|c|c|c|c|}
\hline \multirow{2}{*}{$\begin{array}{l}\text { Field of } \\
\text { questionnaire }\end{array}$} & $\begin{array}{c}\text { Arithmetic } \\
\text { mean }\end{array}$ & $\begin{array}{c}\text { Standard } \\
\text { deviation }\end{array}$ & $\begin{array}{c}\text { Degrees } \\
\text { of } \\
\text { freedom }\end{array}$ & $\begin{array}{c}\text { T } \\
\text { value }\end{array}$ & $\begin{array}{c}\text { Level of } \\
\text { significance }\end{array}$ \\
\hline \multirow{2}{*}{$\begin{array}{l}\text { science } \\
\text { fiction test }\end{array}$} & 48,2 & 9,77 & & & \\
\cline { 2 - 3 } & 55,8 & 8,15 & & & \\
\cline { 2 - 3 } & 44,43 & 10,6 & 30 & 42,66 & 0,05 \\
\hline
\end{tabular}

The above -mentioned table shows the following:-

- The arithmetic mean for all clauses of the science fiction test mentioned in the questionnaire of the science fiction skills whereas the standard deviation was (9.77)so the relative scale was( $79 \%$ ).

- The arithmetic mean for all clauses of the school attainment field mentioned in the auto didactic skills measure caused by the social participations in developing self-skills was (55.8). Whereas, the standard deviation was (8.15), so the relative scale was $(83 \%)$.

- The arithmetic mean for all clauses of the science fiction test. Whereas, the 
standard deviation was (10.6) so the relative scale was $(86 \%)$.

\section{Discussion}

Through analyzing the previous results for the research sample in the science fiction skills Test attainment, it so clear that Creatively for the study sample affects greatly the response to the test due to the following reasons:

- Clarify the importance of the role of imagination and scientific creativity in the sound scientific upbringing of children and providing them with scientific concepts and scientific thinking skills.

- Directing the attention of specialists in education to the need to pay attention to imagination and scientific creativity directly in kindergarten curricula and emphasizing that science fiction is an integral part of the educational process system in kindergarten institutions and directing the attention of the designers of training courses for kindergarten teachers to the necessity of providing professional training courses for teachers related to the importance and development Imagination and scientific creativity in children.

- The current study uses the descriptive approach, in which it identifies the features of the role that kindergarten plays in developing the imagination and scientific creativity of children

\section{Conclusion}

scientific creativity skills are necessary to develop personal and self-aspects for kindergarten children which support the achievement and lead to more thinking skills. And It is important to make good use of science fiction skills and activities in the educational process.

\section{References}

[1] Fleer , Marilyn ,(2013) : Affective Imagination In Science Education : Determining the Emotional

[2] Nature of Scientific and Technological Learning of Young Children, Journal Of Research In Science Education, volume 43 ,issue 5 , pp 2085-2101

[3] Honig,A . (2001) . How to promote creative thinking. Early Childhood Today,15(5),3441.

[4] Laprise, S.\& Winrich, C.(2010). The Impact Of Science Fiction Films on Student In Science, Journal

[5] Of College Science Teaching, 40(2), PP 4549.

[6] Linda.C. Edwards (1995): Affective Development \& The Creative Art, Merrill Publishing Co., Columbus, P.12 .

[7] Shepard Son D.P, Britch S.J (2000):Children Science, Science and Children Nats, vol.(38),No(3) P 29-

[8] Yan \& Leng (2005). An investigation of the relationship between the open-endedness of activities and creativity of young children, university of New Orleans, United States.

[9] Yadav, G., Komal, Sujata, Gandhi, S. \& Mehta, M. (2017). Self behavior of the students. TRACST- International motivational Journal of Commerce, Business and Management (IJCBM), 6(1), 51-53 